\title{
PERIODISMO DEPORTIVO DE LARGO FORMATO EN LA ERA DIGITAL. ANÁLISIS COMPARATIVO DE L'ÉQUIPE EXPLORE Y SPORTS ILLUSTRATED LONGFORM
}

\author{
Long-form sports journalism in the digital era. A \\ comparative analysis of L'équipe explore and Sports \\ illustrated longform
}

Xavier Ramon-Vegas y Christopher Tulloch

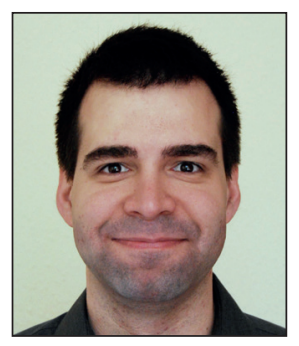

Xavier Ramon-Vegas es profesor e investigador del Departamento de Comunicación de la Universitat Pompeu Fabra (UPF). Doctor en comunicación, es master en estudios avanzados en comunicación social y licenciado en comunicación audiovisual y periodismo por la UPF. Sus líneas de investigación son la ética y la calidad informativa, el periodismo deportivo y los estudios olímpicos. Es miembro del Grup de Recerca en Periodisme y participa en el proyecto competitivo I+D+i Accountability y culturas periodísticas en España. Impacto y propuesta de buenas prácticas en los medios de comunicación españoles (MINECO/FEDER, UE, ref: CSO2015-66404-P).

http://orcid.org/0000-0002-4478-5626

xavier.ramon@upf.edu

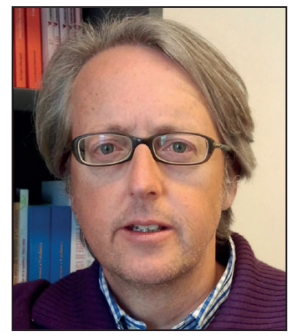

Christopher Tulloch es profesor e investigador del Departamento de Comunicación de la Universitat Pompeu Fabra (UPF). Doctor en periodismo por la UPF, es master en estudios japoneses por las Universidades de Essex y Tokio y licenciado en filología inglesa por la Universidad de York (Reino Unido). Sus líneas de investigación son el periodismo internacional, prensa y transiciones democráticas, corresponsales en el extranjero e innovación periodística y docente. Es miembro del Grup de Recerca en Periodisme y participa en el proyecto competitivo I+D+i PreTrans: El papel de la prensa diaria en la Transición democrática: cobertura informativa y comportamiento político de periódicos y periodistas (Ministerio de Economía y Competitividad, ref. CSO2012-36774). http://orcid.org/0000-0002-5476-0887

christopher.tulloch@upf.edu

Universitat Pompeu Fabra, Departament de Comunicació Roc Boronat, 138. 08018 Barcelona, España

\section{Resumen}

En un escenario mediático caracterizado por la fuerte competencia, los ciclos de producción acelerados y el impacto de las redes sociales, la expansión del contra-género que es el periodismo de largo formato -long form journalism- tiene un protagonismo cada vez más creciente. Medios tradicionales y plataformas nativas digitales han invertido recursos en productos que apuestan por la innovación tecnológica y por técnicas narrativas disociadas del consumo rápido de información. El ámbito deportivo es una de las áreas donde este fenómeno, vinculado con el periodismo lento, ha tenido un impacto más significativo. Teniendo en cuenta este contexto, el artículo examina la colección completa de reportajes de largo formato desarrollados por dos prestigiosos sitios web: L'équipe explore (Francia) y Sports illustrated longform (Estados Unidos). El análisis permite extraer una clasificación de las características que estas plataformas presentan en materia de agenda y fuentes informativas, arquitectura multimedia y estrategias de construcción de marca.

\section{Palabras clave}

Periodismo de largo formato; Periodismo deportivo; Medios digitales; Agenda; Fuentes; Arquitectura multimedia; Construcción de marca.

\footnotetext{
Abstract

In a media landscape characterized by fierce competition, accelerated production cycles, and the impact of social media, the expansion of a counter-genre such as digital long-form journalism, is of growing interest. Both legacy outlets and native
} 
online platforms have invested resources in products that embrace technological innovation and storytelling techniques dissociated from the fast consumption of information. The field of sports is one of the areas where this phenomenon, intertwined with slow journalism, has had a stronger impact. Bearing this context in mind, this article examines the entire collection of long-form stories developed by two prestigious websites: L'équipe explore (France) and Sports illustrated longform (United States). This analysis allows for the classification of the salient features that these websites present in terms of agenda, news sources, multimedia architecture, and brand-building strategies.

\section{Keywords}

Long-form journalism; Sports journalism; Digital media; Agenda; Sources; Multimedia architecture; Brand-building.

Ramon-Vegas, Xavier; Tulloch, Christopher (2016). “Periodismo deportivo de largo formato en la era digital. Un análisis comparativo de L'équipe explore y Sports illustrated longform”. El profesional de la información, v. 25, n. 3, pp. 404-412.

http://dx.doi.org/10.3145/epi.2016.may.10

\section{Introducción}

En los últimos años, la irrupción del periodismo de largo formato ha tenido un fuerte impacto en el escenario informativo digital, incluido el ámbito deportivo (Rojas-Torrijos, 2014; Vogan; Dowling, 2014). Medios tradicionales como The New York times o The guardian y plataformas especializadas como SBNation, ESPN.com, Sports illustrated longform o L'équipe explore han invertido recursos en desarrollar productos innovadores que cuestionan la rapidez de los flujos informativos convencionales y consiguen atraer a los usuarios gracias a la atractiva interfaz y la experiencia multisensorial que ofrece el largo formato.

\section{Medios tradicionales y nativos han apos- tado por productos de largo formato que cuestionan la rapidez informativa y atraen por su atractiva interfaz}

La exitosa integración de elementos multimedia e interactivos en el flujo narrativo de las historias (Barnhurst, 2010; Pauly, 2014; Rue, 2013) ha permitido a estos productos subvertir nociones fuertemente arraigadas en internet, como el hecho que los artículos extensos no funcionan. En una entrevista en 2013, David Remnick, editor de The New Yorker, declaró que el periodismo de largo formato había dado la vuelta a la primera ley de la "teología web": que lo extenso no se consume (Sharp, 2013).

El fenómeno del largo formato digital no debe considerarse de forma aislada, sino que se debe vincular a otras dinámicas contemporáneas de la praxis periodística. En primer lugar, debemos referirnos al "nuevo-nuevo periodismo" (newnew journalism). Este movimiento cuestiona prácticas anti-profesionales como el refrito o "churnalism" (Davies, 2008), retomando ideas del "nuevo periodismo" de los años 60. Sus rasgos distintivos son la profundidad, la inmersión, una mayor atención a la dimensión subjetiva y a los sentimientos de los protagonistas (Neveu, 2014) y un estilo narrativo que incluye la presencia de la voz de los periodistas en los textos (Sims, 2007).

En segunda instancia, el periodismo de largo formato se vincula estrechamente con el periodismo lento (slow journalism). Ambos se caracterizan por la necesidad de disociar el periodismo de la estricta actualidad y del paradigma de la instantaneidad (Rosique-Cedillo y Barranquero-Carretero, 2015); por el interés en la calidad, la precisión, la reflexión, la narrativa, el contexto y la comprobación de fuentes (LeMasurier, 2015); por evitar el sobreuso de materiales de agencia y gabinetes; y por la desaceleración de la periodicidad de publicación debido a los procesos de producción más largos.

Pese a que hasta el momento los académicos han esbozado estos rasgos generales, conviene dar un paso más allá para delimitar de forma más clara y específica las características del periodismo deportivo de largo formato en el escenario digital. El análisis empírico de la producción de las dos publicaciones de referencia en este ámbito (Sports illustrated longform y L'équipe explore) debe ayudarnos en esta tarea.

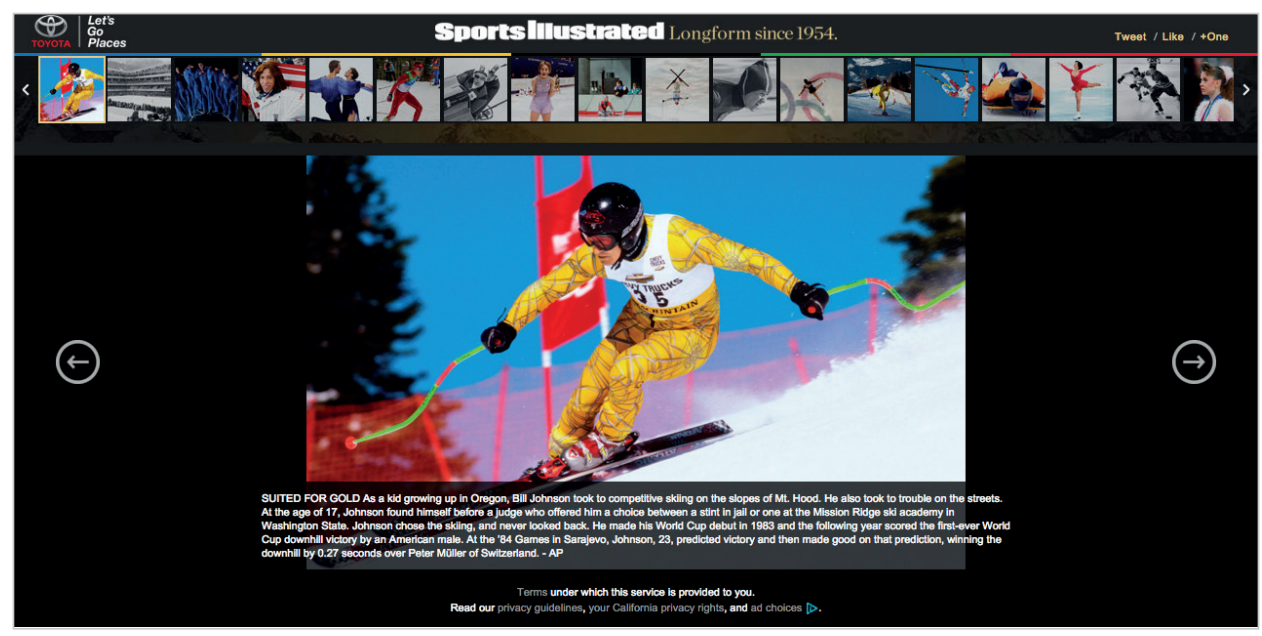

Figura 1. Galería fotográfica sobre los juegos olímpicos de invierno en SI longform 


\section{Metodología}

El objetivo de la investigación ha sido responder a las siguientes preguntas: ¿Cuáles son las características más significativas del periodismo deportivo digital de largo formato en materia de agenda y fuentes informativas, arquitectura multimedia y estrategias de construcción de marca? ¿En qué consiste el cambio de marco narrativo y periodístico que nos propone?

Para dar respuesta a estos interrogantes, los investigadores han empleado la técnica del análisis del contenido (Bryman, 2012; Wimmer y Dominick, 2011). La muestra fue seleccionada de forma no probabilística por los investigadores, que escogieron dos sitios web especializados en periodismo deportivo de largo formato. L'équipe explore (Francia) y Sports illustrated longform (Estados Unidos) fueron considerados teniendo en cuenta como criterios estratégicos el prestigio, la calidad y la trayectoria de sus publicaciones madre (L'équipe y Sports illustrated); la notable difusión de éstas en sus contextos comunicativos; y su apuesta por desarrollar plataformas digitales de largo formato.

La integración de elementos multimedia en el flujo narrativo de las historias subvierte la noción de que los contenidos largos no funcionan en internet

Sports illustrated, propiedad de Time Inc., es considerado uno de los medios deportivos de referencia en Estados Unidos. Desde 1954, la revista ha destacado por su riqueza fotográfica y sus reportajes en profundidad, aspectos que aún impregnan su apuesta periodística. Cuenta con una difusión en papel de 3.044.430 ejemplares y con 27 millones de usuarios únicos en su sitio web ${ }^{1}$. En octubre de 2013 lanzó su plataforma de largo formato:

http://www.si.com/longform
Esta web se presenta bajo el sello "Longform since 1954", una expresión que refuerza la identidad de marca de la empresa sugiriendo que "la revista ha estado produciendo tales obras complejas desde décadas" (Downling; Vogan, 2015 , p. 217). Hasta octubre de 2015, SI longform ha publicado 51 reportajes (2,04 por mes).

\section{El largo formato se aleja de la redundan-} cia y similitud que tan frecuentemente se encuentra en los contenidos deportivos de actualidad

L'équipe es un prestigioso periódico francés, creado en 1947 como sucesor del diario L'auto, inicialmente fundado en 1900 como L'auto-vélo. El medio, propiedad de Éditions Philippe Amaury, se concentra principalmente en fútbol, ciclismo, rugby y motor. Se trata del periódico deportivo con mayor difusión en Francia, con 217.456 ejemplares. Su web presenta una audiencia de 5,6 millones de usuarios únicos². L'équipe es reconocido como un medio "de calidad que proporciona una excelente cobertura de la información deportiva con la que ningún otro periódico generalista puede competir" (Ranc, 2012, p. 40). L'équipe explore, el sitio dedicado a los reportajes de largo formato e interactividad, se lanzó en abril de 2013.

http://www.lequipe.fr/explore

Desde entonces se han publicado 32 reportajes $(0,74$ por mes).

El objeto de estudio ha sido la colección completa de reportajes en profundidad de L'équipe explore y de Sports illustrated longform $(n=83)$, publicados desde la creación de ambos sitios web hasta octubre de 2015. Para llevar a cabo el análisis empírico se diseñaron dos instrumentos metodológicos: un libro y una ficha de codificación. El libro permitió especificar con detalle los criterios utilizados para evaluar

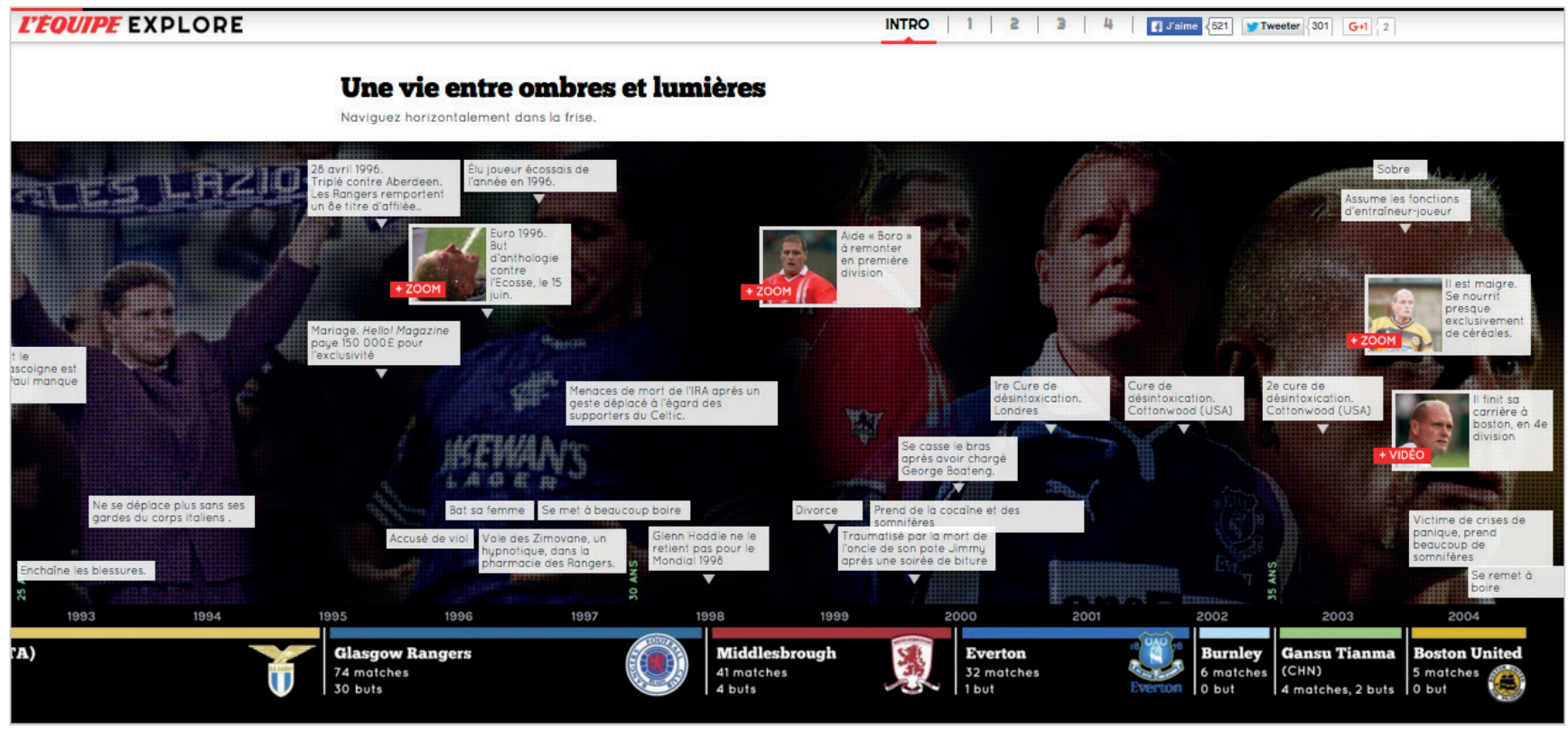

Figura 2. Cronología sobre la carrera de Paul Gascoigne, publicada en L'équipe explore 
Tabla 1. Agenda deportiva en Sports illustrated longform y L'équipe explore

\begin{tabular}{|c|c|c|c|c|}
\hline \multirow[b]{2}{*}{ Deporte } & \multicolumn{2}{|c|}{ SI longform } & \multicolumn{2}{|c|}{ L'équipe explore } \\
\hline & $\begin{array}{c}\mathrm{n}^{\circ} \mathrm{de} \\
\text { piezas }\end{array}$ & $\%$ & $\begin{array}{c}n^{\circ} \text { de } \\
\text { piezas }\end{array}$ & $\%$ \\
\hline Ajedrez & 0,00 & 0,00 & 1,00 & 3,13 \\
\hline Alpinismo & 0,00 & 0,00 & 1,00 & 3,13 \\
\hline Atletismo & 2,25 & 4,41 & 2,00 & 6,25 \\
\hline Baloncesto & 12,25 & 24,02 & 2,00 & 6,25 \\
\hline Béisbol & 6,25 & 12,25 & 0,00 & 0,00 \\
\hline Boxeo & 3,00 & 5,88 & 1,00 & 3,13 \\
\hline Buceo libre & 0,00 & 0,00 & 1,00 & 3,13 \\
\hline Carreras de ultrafondo & 0,00 & 0,00 & 1,00 & 3,13 \\
\hline Ciclismo & 0,00 & 0,00 & 5,00 & 15,63 \\
\hline Deportes de invierno & 4,00 & 7,84 & 1,00 & 3,13 \\
\hline Equitación & 2,00 & 3,92 & 1,00 & 3,13 \\
\hline Fútbol & 4,00 & 7,84 & 5,00 & 15,63 \\
\hline Fútbol americano & 10,25 & 20,10 & 0,00 & 0,00 \\
\hline Golf & 0,00 & 0,00 & 1,00 & 3,13 \\
\hline Hockey & 3,00 & 5,88 & 0,00 & 0,00 \\
\hline Lucha / Lucha libre & 1,00 & 1,96 & 1,00 & 3,13 \\
\hline Motor & 1,00 & 1,96 & 1,00 & 3,13 \\
\hline Pesca & 1,00 & 1,96 & 0,00 & 0,00 \\
\hline Rodeo & 1,00 & 1,96 & 0,00 & 0,00 \\
\hline Rugby & 0,00 & 0,00 & 4,00 & 12,50 \\
\hline Salto base & 0,00 & 0,00 & 1,00 & 3,13 \\
\hline Surf & 0,00 & 0,00 & 1,00 & 3,13 \\
\hline Tenis & 0,00 & 0,00 & 1,00 & 3,13 \\
\hline Vela & 0,00 & 0,00 & 1,00 & 3,13 \\
\hline Total & 51,00 & 100,00 & 32,00 & 100,00 \\
\hline
\end{tabular}

cada categoría. Después, se creó una ficha de codificación mediante Google Form, que permitió registrar los aspectos relevantes de cada reportaje.

\section{El largo formato es un espacio clave para desafiar la poca variedad de fuentes in- formativas en el periodismo deportivo}

Una vez codificada la totalidad de la muestra, los investigadores exportaron el contenido de la base de datos a un fichero Microsoft Excel. Durante la primera semana de noviembre de 2015 se procedió a extraer los datos cuantitativos y cualitativos, generando las tablas, ejemplos y observaciones que permitieron dar respuesta a las preguntas de investigación. Finalmente, siguiendo las indicaciones de Brennen (2013, p. 24), se analizaron e interpretaron los resultados y se redactaron las conclusiones del análisis.

\section{Resultados}

Este estudio ha permitido obtener una radiografía pormenorizada del tratamiento desarrollado por L'équipe explore y Sports illustrated longform y extraer un listado de las ca- racterísticas más destacadas del periodismo deportivo de largo formato en el escenario digital. La presentación de los resultados se estructura en tres ejes: (1) la agenda y las fuentes informativas; (2) la arquitectura multimedia; y (3) las estrategias de construcción de marca.

\subsection{Agenda y fuentes informativas}

\section{Deportes tratados}

El largo formato se ha revelado como una oportunidad para proporcionar un menú deportivo más amplio en L'équipe explore, donde se han cubierto 19 deportes en sólo 32 artículos. Este no ha sido el caso de SI longform, donde los datos muestran que no sólo se cubren menos deportes (13 en 51 piezas) sino que más de la mitad de los reportajes (56,37\%) se dedican al baloncesto, béisbol y fútbol americano. Pese a que L'équipe también ha priorizado disciplinas mayoritarias en su producto en papel como el ciclismo, el fútbol y el rugby, el proyecto de Sports illustrated demuestra ser mucho más conservador en sus decisiones editoriales.

Dicho esto, cabe reconocer que ambas publicaciones han proporcionado ángulos alternativos a estos deportes destacados, alejándose de la redundancia, uniformidad y similitud que tan frecuentemente se puede encontrar en los contenidos deportivos de actualidad (English, 2014). Esto se ha conseguido a través de dos ejes constantes: la (re) creación de la historia deportiva y la construcción de la dimensión humana de los atletas. Respecto a la primera cuestión, SI longform ha publicado un gran número de temas históricos e intergeneracionales, incluyendo la serie 'Great year in sports', que utiliza la idea de la "cápsula de tiempo" para transportar al lector al año 1985. Por su parte, L'équipe explore ha revisitado momentos remarcables como la participación de Brasil en mundial de fútbol de 1970 o la victoria de Francia sobre Nueva Zelanda en la copa del mundo de rugby de 1999. Este énfasis refuerza la idea que el periodismo de largo formato se interesa tanto por cuestiones contemporáneas como históricas (Le-Masurier, 2015).

En referencia al segundo aspecto, pese a que han prevalecido las historias sobre superación personal, la tragedia también está presente a través de temas como las muertes del jugador de beisbol Donnie Moore o de Bison Dele, exjugador de la NBA. En una escala menos dramática pero también negativa, también se muestran ejemplos de fracaso, como en los casos de los futbolistas Tim Tebow o Dan Marino. Lo que une a estas historias es el foco en la dimensión humana.

Los deportes minoritarios también han encontrado su sitio en estas publicaciones, que pretenden así ampliar la cultura deportiva de sus lectores. Disciplinas como la pesca, la equitación, el rodeo y la lucha libre aparecen en el caso americano, mientras que otras como el alpinismo, vela, surf, ajedrez, salto base o el buceo libre son recogidas por L'équipe. El uso inteligente de recursos multimedia es muy importante puesto que el autor debe convencer del interés del tema a un lector que posiblemente no está habituado a consumir estos deportes en su día a día.

\section{Nacionalidad y género de los protagonistas}

Debido a la lógica económica de las empresas mediáticas y al criterio de proximidad, los medios tienden a cubrir los 


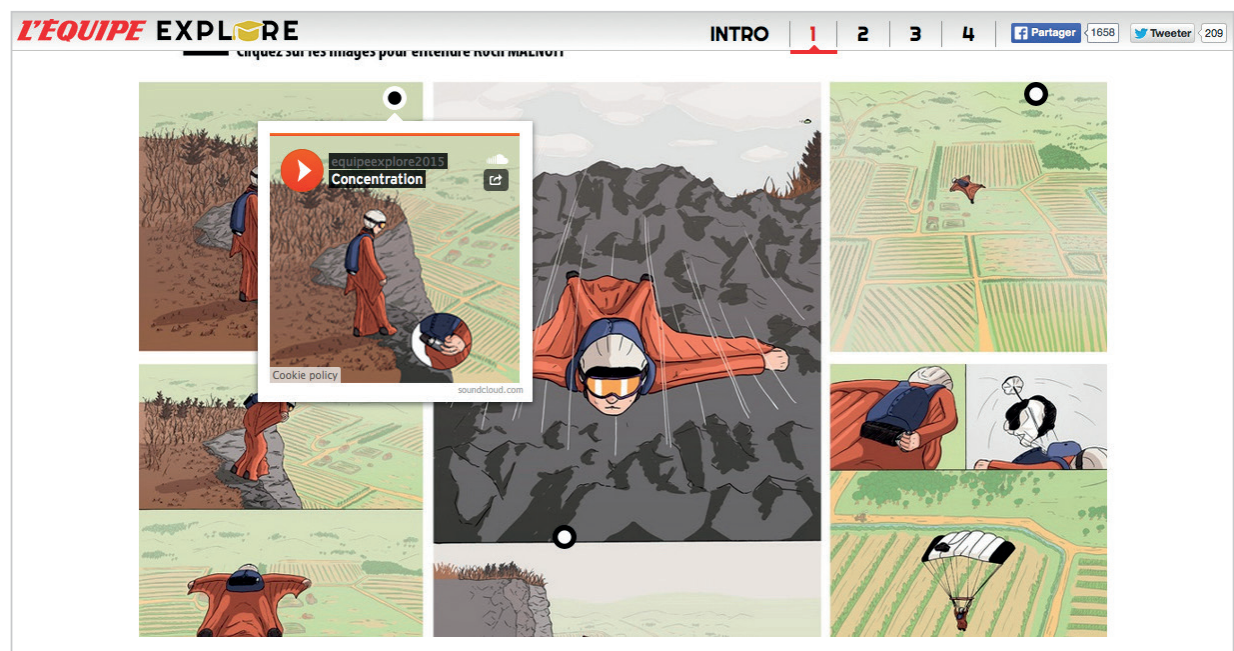

Figura 3. Collage interactivo con audios incrustados, publicado en L'équipe explore decisivo en tender puentes de respeto entre Irlanda del Norte y la República de Irlanda. Otro caso relevante se encuentra en 'On the edge', un reportaje que explica las deterioradas relaciones entre Georgia y Rusia. Por lo que respecta al impacto económico del deporte, Sports illustrated ahondó en la industria de la pesca y el efecto del regreso del baloncestista Lebron James a Cleveland.

Otros aspectos contextuales relevantes incluyen: cultura (cultura urbana en Estados Unidos); comunicación (radiodifusión deportiva, acuerdos

deportistas nacionales (Billings; Kim, 2014). Sin embargo, el alto grado de etnocentrismo mostrado por Sports illustrated (donde los atletas norte americanos fueron protagonistas del $82,35 \%$ de los artículos) limita de forma remarcable las posibilidades de transcender el mercado nacional. En contraste, L'équipe demuestra una clara vocación internacional, donde un $68,75 \%(n=22)$ de los temas fueron dedicados a deportistas no franceses.

En coherencia con la tradicional minimización de la mujer en el periodismo deportivo (O'Neill; Mulready, 2015), el estudio demuestra la ausencia de las deportistas en estas plataformas. Sólo un reportaje de 83 se dedicó exclusivamente a una mujer. Además, las redactoras fueron prácticamente inexistentes. En correlación con la infrarrepresentación de la mujer en las organizaciones mediáticas (Whiteside; Hardin, 2013), entre los 70 autores codificados en la muestra, sólo una mujer (Anne-Sophie Bourdet, de L'équipe) escribió un reportaje.

\section{Cuestiones contextuales}

El denominador común de ambas plataformas de largo formato es su capacidad para expandir la cobertura a toda la complejidad y las cuestiones significativas de carácter contextual vinculadas a los temas tratados. 'Ghost of Speedy Cannon' permitió a los lectores saber más sobre el clima de racismo hacia los afroamericanos en Alabama en los años 70. En cuestiones de salud, reportajes centrados en fútbol americano y rugby ayudaron a expandir el debate sobre los efectos negativos que tienen las conmociones cerebrales. Respecto a cuestiones geopolíticas e históricas, mediante el artículo 'You go football', L'équipe contextualizó las consecuencias de la guerra de los Balcanes. En 'L'appel de l'Irlande', el mismo medio ahondó en el conflicto político irlandés y como el equipo de rugby ha jugado un papel
Tabla 2. Tipos de fuentes informativas utilizadas en los reportajes

\begin{tabular}{|l|c|c|c|c|}
\hline \multicolumn{1}{|c|}{ Fuentes } & \multicolumn{2}{c|}{ SI longform } & \multicolumn{2}{c|}{ L'équipe explore } \\
\hline & $\begin{array}{c}\text { n. de } \\
\text { piezas }\end{array}$ & $\%$ & $\begin{array}{c}\text { n. de } \\
\text { piezas }\end{array}$ & $\%$ \\
\hline Reporteros deportivos & 26 & 50,98 & 10 & 31,25 \\
\hline Periodistas/editores de otras secciones & 5 & 9,80 & 3 & 9,38 \\
\hline Deportistas & 23 & 45,10 & 24 & 75,00 \\
\hline Ex deportistas & 33 & 64,71 & 25 & 78,13 \\
\hline Entrenadores & 32 & 62,75 & 23 & 71,88 \\
\hline Instituciones / organizaciones & 21 & 41,18 & 21 & 65,63 \\
\hline Empresas privadas & 7 & 13,73 & 5 & 15,63 \\
\hline Agencias de noticias & 24 & 47,06 & 11 & 34,38 \\
\hline Medios de comunicación & 28 & 54,90 & 21 & 65,63 \\
\hline Webs & 4 & 7,84 & 1 & 3,13 \\
\hline Blogs y redes sociales & 2 & 3,92 & 2 & 6,25 \\
\hline Académicos, expertos y analistas & 7 & 13,73 & 11 & 34,38 \\
\hline Libros y publicaciones especializadas & 13 & 25,49 & 14 & 43,75 \\
\hline Otras fuentes & 26 & 50,98 & 17 & 53,13 \\
\hline
\end{tabular}

de la NBC con los deportistas americanos); tecnología (aerodinámica en ciclismo, métrica en béisbol); seguridad (crimen y violencia de género en Suráfrica); derechos humanos (aspectos negativos de los juegos olímpicos de Sochi 2014; crítica de Gary Kasparov hacia las violaciones de derechos humanos en Rusia), entre otros.

\section{Fuentes informativas}

Sports illustrated y L'équipe han usado una media de 4,92 y 5,81 tipos de fuentes en cada uno de sus reportajes. Estos resultados indican que las plataformas de largo formato son espacios cruciales para superar las nociones arraigadas del periodismo deportivo como un área caracterizada por el uso escaso de fuentes informativas diferentes (Rowe, 2007). Como se esperaba, los actores deportivos (ex deportistas, deportistas, entrenadores) fueron los más consultados. Sin embargo, un amplio abanico de otros tipos de fuentes (ver tabla 2) ha sido muy útil para proporcionar el bagaje necesa- 
rio para desarrollar los reportajes. Sorprendentemente, los sitios web, blogs y redes sociales se encuentran entre las fuentes con menos presencia, pese a su fuerte impacto en la práctica actual del periodismo deportivo (Boyle; Haynes, 2014; English, 2016).

\subsection{Arquitectura multimedia}

La convergencia multimedia (Jenkins, 2006) es una característica fundamental de los reportajes de largo formato. Ambas plataformas estudiadas han combinado cuidadosamente el texto con imágenes, vídeo y elementos multimedia para ofrecer sus productos.

\section{Estructura}

SI longform ha priorizado el modelo de desplazamiento vertical, incluyendo Parallax, un tipo de efecto en que el fondo se mueve más lentamente que el primer plano (Dowling; Vogan, 2015). L'équipe ha empleado regularmente una aproximación híbrida, que permite a los usuarios decidir si quieren desplazarse verticalmente o acceder a los capítulos, una técnica que ayuda a trocear las historias largas en fragmentos más manejables. L'équipe también ha publicado ocho piezas en que vídeos de más de 20 minutos funcionan como recursos centrales de los reportajes.

\section{El largo formato aporta prestigio y per-} mite expandir el alcance demográfico y la cuota de mercado de las empresas que lo publican

\section{Textos}

La extensión no necesariamente implica calidad, pero el periodismo deportivo literario requiere un cierto espacio (Le-Masurier, 2015). A grandes rasgos, L'équipe explore ha publicado piezas más largas que SI longform. En el sitio web francés, los artículos comprendidos entre los 40.001 y 75.000 caracteres han representado el $65,63 \%$ de la producción. Dicho esto, los tres artículos más largos en toda la muestra se publicaron en SI longform.

Cabe puntualizar que los hipervínculos han sido escasamente empleados, pese a su centralidad en el periodismo digital. En SI longform, $94,12 \%$ de las piezas $(n=48)$ no incluye ningún vínculo url. Del mismo modo, en L'équipe explore, $78,13 \%$ de ellas $(n=25)$ no aporta vínculo alguno. Pese a que los dos medios buscan publicar productos autónomos, la ausencia de vínculos limita las oportunidades de los usuarios de obtener información adicional de otras plataformas en línea.

\section{Elementos multimedia}

Centrándonos en los componentes extra-textuales, SI longform y L'équipe explore han empleado respectivamente 27,04 y 31,47 imágenes por reportaje. Los vídeos también han sido elementos cruciales de la narrativa de largo formato proporcionada por ambas plataformas. En SI longform, $66,67 \%$ de las piezas incluyen material audiovisual. 189
Tabla 3. Extensión de los textos publicados en SI longform y L'Équipe explore

\begin{tabular}{|l|c|c|c|c|}
\cline { 2 - 5 } \multicolumn{1}{c|}{} & \multicolumn{2}{c|}{ SI longform } & \multicolumn{2}{c|}{ L'équipe explore } \\
\hline $\begin{array}{c}\text { Extensión de los artículos } \\
\text { (caracteres) }\end{array}$ & $\begin{array}{c}\text { n. de } \\
\text { piezas }\end{array}$ & $\%$ & $\begin{array}{c}\text { n. de } \\
\text { piezas }\end{array}$ & $\%$ \\
\hline Menos de 20.000 & 6 & 11,76 & 8 & 25,00 \\
\hline 20.001 a 40.000 & 27 & 52,94 & 3 & 9,38 \\
\hline 40.001 a 60.000 & 13 & 25,49 & 18 & 56,25 \\
\hline 60.001 a 75.000 & 2 & 3,92 & 3 & 9,38 \\
\hline Más de 75.000 & 3 & 5,88 & 0 & 0,00 \\
\hline Total & 51 & 100,00 & 32 & 100,00 \\
\hline
\end{tabular}

Tabla 4. Extensión de los vídeos publicados

\begin{tabular}{|l|c|c|c|c|}
\cline { 2 - 5 } \multicolumn{1}{c|}{} & \multicolumn{2}{c|}{ SI longform } & \multicolumn{2}{c|}{ L'équipe explore } \\
\hline $\begin{array}{c}\text { Extensión de los vídeos } \\
\text { publicados }\end{array}$ & $\begin{array}{c}\text { n. de } \\
\text { piezas }\end{array}$ & $\%$ & $\begin{array}{c}\text { n. de } \\
\text { piezas }\end{array}$ & $\%$ \\
\hline Ningún vídeo publicado & 17 & 33,33 & 0 & 0,00 \\
\hline 1 minuto o menos & 4 & 7,84 & 1 & 3,13 \\
\hline 1 a 5 minutos & 7 & 13,73 & 0 & 0,00 \\
\hline 5 a 10 minutos & 9 & 17,65 & 2 & 6,25 \\
\hline más de 10 minutos & 14 & 27,45 & 29 & 90,63 \\
\hline Total & 51 & 100,00 & 32 & 100,00 \\
\hline
\end{tabular}

Tabla 5. Número de piezas en que se utilizaron elementos multimedia

\begin{tabular}{|l|c|c|c|c|}
\cline { 2 - 5 } \multicolumn{1}{c|}{} & \multicolumn{2}{c|}{ SI longform } & \multicolumn{2}{c|}{ L'équipe explore } \\
\hline Elementos multimedia & $\begin{array}{c}\text { n. de } \\
\text { piezas }\end{array}$ & $\%$ & $\begin{array}{c}\text { n. de } \\
\text { piezas }\end{array}$ & $\%$ \\
\hline Imágenes & 51 & 100,00 & 32 & 100,00 \\
\hline Vídeos & 34 & 66,67 & 32 & 100,00 \\
\hline Fotogalerías & 22 & 43,14 & 13 & 40,63 \\
\hline Cronologías & 7 & 13,73 & 7 & 21,88 \\
\hline Mapas & 2 & 3,92 & 11 & 34,38 \\
\hline Infografías & 3 & 5,88 & 26 & 81,25 \\
\hline Vídeos interactivos & 0 & 0,00 & 1 & 3,13 \\
\hline Audios & 9 & 17,65 & 3 & 9,38 \\
\hline Otras aplicaciones multimedia & 8 & 15,69 & 9 & 28,13 \\
\hline
\end{tabular}

vídeos se han publicado en 34 reportajes (5,56 vídeos por pieza). Por su parte, L'équipe explore ha incluido 217 vídeos en 32 piezas, lo que revela que el sitio francés ha hecho un uso más intensivo de este tipo de materiales $(6,78$ vídeos por pieza). L'équipe también ha proporcionado tratamientos de vídeo más largos, mayoritariamente por encima de los 10 minutos de duración $(90,63 \%$ de las piezas).

Más allá de las imágenes y vídeos, L'équipe y Sports illustrated han hecho un esfuerzo para traspasar los límites convencionales de la narrativa deportiva, haciendo un uso intensivo de elementos multimedia (ver tabla 5). Las dos organizaciones han encontrado un punto medio entre los excesos del innovador pero logísticamente irrepetible 'Snowfall' de John Branch en The New York times y la incorporación aleatoria de material extra-textual. En los reportajes estudiados, el uso del multimedia es controlado, relevante y didácticamente justificable. 


\section{The People and Their Stories}

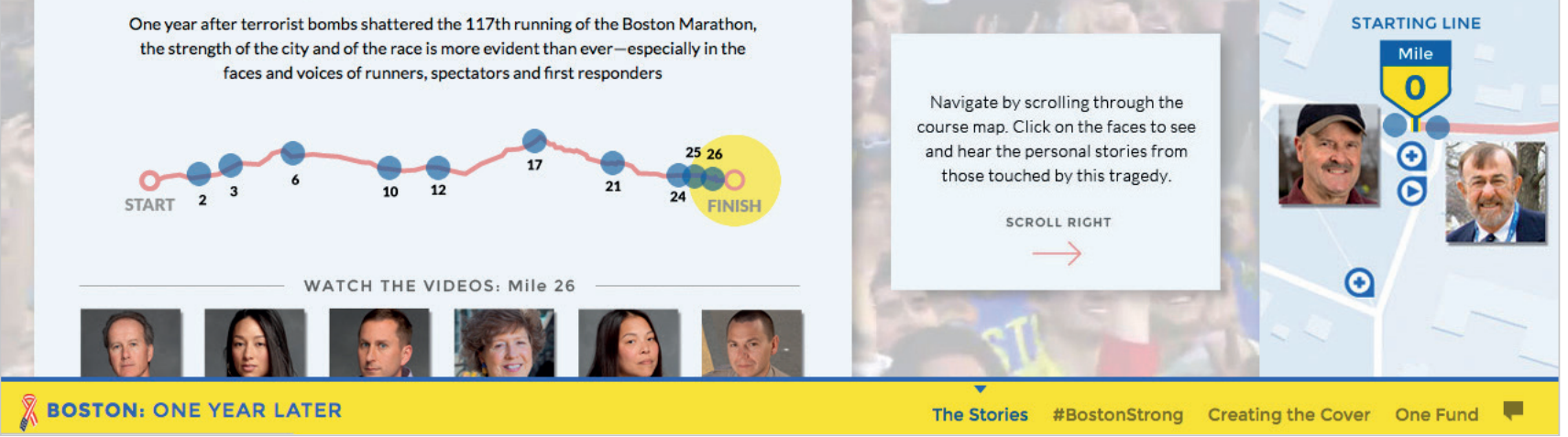

Figura 4. Reportaje interactivo sobre la maratón de Boston

El valor fundamental que estas herramientas aportan para mejorar la calidad de la información no se debe subestimar. En primer lugar, las galerías fotográficas permiten a los lectores revisitar momentos y protagonistas clave en la historia del deporte, como los deportistas olímpicos más destacados en los juegos de invierno desde Cortina 1956 hasta Vancouver 2010. En segundo lugar, las cronologías permiten a los usuarios navegar a través de las carreras de los deportistas y la historia de las competiciones. Un ejemplo interesante se encuentra en 'Looking for Gazza', donde una cronología ilustra la vida del futbolista Paul Gascoigne, desde su nacimiento en 1967 hasta su retiro en 2004.

En tercera instancia, atractivos infográficos, especialmente en L'équipe, son cruciales en la estrategia de mejorar la riqueza del contenido y explicar datos específicos. Por ejemplo, en 'Tahiti Surf Club', un gráfico compuesto por dos imágenes explica la formación de la ola Teahupoo, una de las mecas del surf.

L'équipe explore introdujo un vídeo interactivo en la pieza 'Signé Sugar Ray'. En este vídeo de 24 minutos, los usuarios pueden consultar materiales adicionales cuando aparecen en la pantalla. Más concretamente, pueden leer y descargar en PDF artículos publicados en abril de 1987 en L'équipe ma-

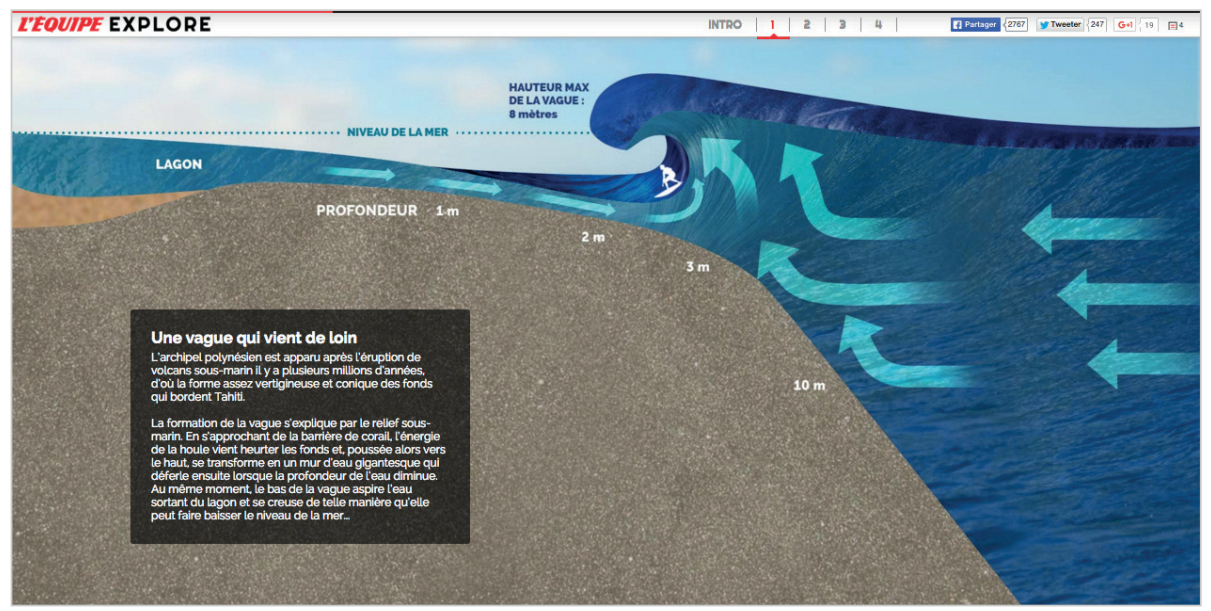

Figura 5. Infografía que ilustra la formación de la ola Teahupoo gazine así como páginas históricas previamente publicadas en el periódico en papel.

Sin embargo, si queremos observar dos ejemplos de reportajes completamente interactivos, nos debemos referir a $\mathrm{SI}$ longform. El primer reportaje interactivo, 'Sending our very best', permite a los usuarios explorar los perfiles de 26 deportistas que participaron en Sochi 2014. El segundo, titulado 'Boston: One year later' permite a los usuarios escoger entre utilizar un patrón narrativo lineal o navegar a través del mapa de la maratón de Boston, con el objetivo de descubrir materiales textuales y visuales sobre las personas que vivieron la 117ạ edición de la maratón, marcada por la tragedia ocasionada por dos bombas terroristas.

Todos los elementos mencionados (así como otros como collages interactivos hechos con Thinglink, audios incrustados con SoundCloud o mapas interactivos) permiten a los usuarios ahondar en las historias o saltar elementos en los que tengan menos interés. La sensación de control y la habilidad de explorar los temas de forma personalizada resulta atractivo para el público.

\subsection{Estrategias de construcción de marca}

Finalmente, la naturaleza autorreferencial (Bordieu, 2010) de muchas de las historias se revela como una característica esencial de los proyectos de largo formato. Sports illustrated longform ha priorizado sus secciones "From the vault" (desde el sótano) y "1985" incluyendo sus autoproclamados "artículos clásicos", en un intento estratégico de vincular historia, tradición, autoridad y prestigio. Algunos reportajes también contienen vídeos incluidos en el canal de Sports illustrated $T V$. Además, algunos de los periodistas se convierten en protagonistas de las historias. Tres 
ejemplos notables son: el entrenamiento de 363 días de Michael McKnight para aprender a encestar en baloncesto; el reportaje del fotógrafo de Sports illustrated Neil Leifer; o la compra por parte del redactor Alexander Wolff de un equipo de baloncesto. Por su parte, L'équipe explore ha hecho varias referencias a artículos originalmente publicados en L'équipe o L'équipe magazine.

Esta constante auto-citación forma parte del despliegue del periodismo de largo formato como una herramienta de construcción de marca. En un mercado cada vez más competitivo, el largo formato es una oportunidad estratégica para ampliar el alcance demográfico y la cuota de mercado de las empresas mediáticas. Pese a que "los reportajes digitales de largo formato operan a menudo como líderes de pérdidas de sus empresas matrices", también aportan un "capital simbólico que conduce a beneficios económicos de formas menos directas" (Vogan; Dowling, 2014, p. 4).

\section{Discusión y conclusiones}

Este artículo ha contextualizado el surgimiento del periodismo de largo formato en la era digital, un fenómeno vinculado con el slow journalism y otras dinámicas contemporáneas en la profesión. El análisis de los reportajes publicados por L'équipe explore y Sports illustrated ha revelado múltiples semejanzas y diferencias entre ambas publicaciones. En un sentido más amplio, el estudio ha permitido a los investigadores identificar y sistematizar las características más significativas del periodismo deportivo de largo formato digital (ver tabla 6).

La investigación revela que en un escenario caracterizado por la comunicación "rápida e instantánea" (Le-Masurier, 2015, p. 138) y la saturación del mercado informativo (Manfredi et al., 2015), el periodismo deportivo de largo formato representa un espacio alternativo para articular un producto diferenciado. Distanciándose del paradigma de la rapidez, sitios web como los analizados ofrecen grandes oportunidades para ampliar la agenda, transcender la uniformidad de los temas tratados, y emplear un amplio abanico de fuentes informativas. Además, estas plataformas ofrecen a los usuarios narrativas más largas y ricas, que explotan las posibilidades que los recursos multimedia y mejoran la calidad y el atractivo de la información. Dejando de lado estas cuestiones, desde una perspectiva de posicionamiento de marca, el largo formato es una opción que aporta prestigio a la estereotipada baja reputación del periodismo deportivo (Rowe, 2007) y que sirve para expandir el alcance demográfico y la cuota de mercado de las empresas que los producen.

Este estudio contribuye al debate emergente sobre el periodismo deportivo de largo formato. Llegados a este punto, será necesario ir más lejos y seguir monitorizando de forma longitudinal la cobertura llevada a cabo por L'équipe explore y Sports illustrated longform. Además, en futuras investigaciones se deberá ampliar el análisis para incluir los contenidos de largo formato desarrollados por medios de información general y plataformas especializadas en múltiples contextos periodísticos, entre ellas ESPN.com, SBNation o $N B C$ SportsWorld. Ello permitirá enriquecer y refinar la tabla de características presentada en este estudio.
Tabla 6. Características de las plataformas de periodismo deportivo de largo formato

\begin{tabular}{|l|}
\hline \multicolumn{1}{c|}{ Agenda y fuentes informativas } \\
\hline - $\begin{array}{l}\text { Posibilidad de ampliar la agenda y de reforzar los deportes cubiertos } \\
\text { por los medios tradicionales }\end{array}$ \\
- $\begin{array}{l}\text { Búsqueda de ángulos alternativos para transcender la uniformidad: } \\
\text { (re)creación de la historia y construcción de la dimensión humana }\end{array}$ \\
- $\begin{array}{l}\text { Capacidad para explicar las historias deportivas en un contexto más } \\
\text { amplio }\end{array}$ \\
- Amplia variedad de fuentes utilizadas (5-6 tipos de fuentes por re- \\
portaje) \\
- Uso limitado de webs, blogs y redes sociales como fuentes \\
\hline - Variedad de estructuras (desplazamiento vertical, capítulos, piezas \\
centradas en vídeos) \\
- Textos largos (incluso pueden llegar a superar los 75.000 caracteres) \\
- Escasez de hipervínculos \\
- Gran número de imágenes utilizadas (más de 25 imágenes por pieza) \\
- Fragmentación del material audiovisual (5-6 vídeos por pieza) \\
- Prioridad a los tratamientos de vídeo largos \\
- Uso intensivo de recursos multimedia e interactivos \\
\hline \multicolumn{1}{c}{ Estrategias de creación de marca } \\
\hline - Naturaleza auto-referencial de las historias (referencias a artículos \\
publicados, materiales clásicos, canales de vídeo, redactores como \\
\hline
\end{tabular}

La triangulación del análisis del contenido con entrevistas con representantes de los medios de comunicación (editores y periodistas) debe permitir un examen profundo de los costes de producción y recursos invertidos en estas plataformas, las culturas periodísticas donde éstas se desarrollan y los procesos de creación. Entrevistas con los usuarios permitirán discernir las expectativas de los lectores, saber cómo es su experiencia como consumidores y saber cómo interactúan con las narrativas digitales de largo formato. Este conocimiento permitirá realizar una proyección sólida sobre la futura consolidación de este fenómeno.

\section{Notas}

1. Los datos sobre difusión en papel de Sports illustrated se pueden encontrar en Alliance for Audited Media:

http://abcas3.auditedmedia.com/ecirc/magtitlesearch.asp

El número de usuarios únicos en la versión digital del medio puede consultarse en:

http://www.simediakit.com/home/digital

2. Las cifras de difusión de L'équipe son proporcionadas por L'Alliance pour les Chiffres de la Presse et des Médias: http://www.ojd.com/Chiffres/La-Presse/La-Presse-Payante/Presse-Quotidienne-Nationale

El volumen de tráfico web de L'équipe.fr puede consultarse en la página de la empresa editora: http://www.amaury.com/lequipe.shtml

\section{Bibliografía}

Barnhurst, Kevin G. (2010). "The form of reports on US newspaper Internet sites, an update". Journalism studies, v. 11 , n. 4 , pp. $555-566$.

http://dx.doi.org/10.1080/14616701003638426 
Billings, Andrew C.; Kim, Youngju (2014). "Shaping viewer experiences. The biggest spectacle on television's grandest stage". En: Girginov, Vassil (ed.). Handbook of the London 2012 olympic and paralympic games. Volume Two: Celebrating the games. Abingdon: Routledge, pp. 184-194. ISBN: 9780415671927

Bourdieu, Pierre (2010). Distinction. A social critique of the judgment of taste. Londres: Routledge. ISBN: 9780415567886

Boyle, Raymond; Haynes, Richard (2014). "Sport, public relations and social media". En: Billings, Andrew C.; Hardin, Marie (ed.). Routledge Handbook of sport and new media. New York: Routledge, pp. 133-142. ISBN: 9780415532761

Brennen, Bonnie (2013). Qualitative research methods for media studies. New York: Routledge. ISBN: 9780415890229

Bryman, Alan (2012). Social research methods (4 $4^{\text {th }}$ ed). Oxford: Oxford University Press. ISBN: 9780199588053

Davies, Nick (2009). Flat earth news. Londres: Vintage. ISBN: 9780099512684

Dowling, David; Vogan, Travis (2015). "Can we "Snowfall" this? Digital longform and the race for the tablet market". Digital journalism, v. 3, n. 2, pp. 209-224.

http://dx.doi.org/10.1080/21670811.2014.930250

English, Peter (2014). "The same old stories: Exclusive news and uniformity of content in sports coverage". International journal of sports communication, v. 7, n. 4, pp. 477-494. http://dx.doi.org/10.1123/IJSC.2014-0026

English, Peter (2016). "Twitter's diffusion in sports journalism: Role models, laggards and followers of the social media innovation". New media \& society, v. 18, n. 3, pp. 484-501. http://dx.doi.org/10.1177/1461444814544886

Jenkins, Henry (2006). Convergence culture: Where old and new media collide. New York: New York University Press. ISBN: 9780814743072

Le-Masurier, Megan (2015). "What is slow journalism?". Journalism practice, v. 9, n. 2, pp. 138-152.

http://dx.doi.org/10.1080/17512786.2014.916471

Manfredi-Sánchez, Juan-Luis; Rojas-Torrijos, José-Luis; Herranz-de-la-Casa, José-María (2015). “Innovación en el periodismo emprendedor deportivo. Modelo de negocio y narrativas". El profesional de la información, v. 24, n. 3, pp. 265-273.

http://dx.doi.org/10.3145/epi.2015.may.06

Neveu, Erik (2014). "Revisiting narrative journalism as one of the futures of journalism". Journalism studies, v. 15, n. 5, pp. 533-542.

http://dx.doi.org/10.1080/1461670X.2014.885683
O'Neill, Deirdre; Mulready, Matt (2015). "The invisible woman? A comparative study of women's sports coverage in the UK national press before and after the 2012 olympic games". Journalism practice, v. 9, n. 5, pp. 651-668. http://dx.doi.org/10.1080/17512786.2014.965925

Pauly, John J. (2014). "The new journalism and the struggle for interpretation". Journalism, v. 15, n. 5, pp. 589-604.

http://dx.doi.org/10.1177/1464884914529208

Rojas-Torrijos, José Luis (2014). "Periodismo deportivo. Nuevas tendencias y perspectivas de futuro". Correspondencias \& análisis, n. 4, pp. 177-190.

http://www.correspondenciasyanalisis.com/es/pdf/v4/ pe/3_periodismo_deportivo.pdf

Ranc, David (2012). Foreign players and football supporters: The Old Firm, Arsenal, Paris Saint-Germain. Oxford: Oxford University Press. ISBN: 9781847794277

Rowe, David (2007). "Sports journalism: Still the 'toy department' of the news media?". Journalism, v. 8, n. 4, pp. 385-405.

http://dx.doi.org/10.3145/10.1177/1464884907078657

Rosique-Cedillo, Gloria; Barranquero-Carretero, Alejandro (2015). "Periodismo lento (slow journalism) en la era de la inmediatez. Experiencias en Iberoamérica". El profesional de la información, v. 24, n. 4, pp. 451-462.

http://dx.doi.org/10.3145/epi.2015.jul.12

Rue, Jeremy (2013). "The 'Snow fall' effect and dissecting the multimedia longform narrative". Multimedia shooter. http://multimediashooter.com/wp/2013/04/21/the-snowfall-effect-and-dissecting-the-multimedia-longform-narrative

Sharp, Naomi (2013). "The future of longform". Columbia journalism review.

http://www.cjr.org/behind_the_news/longform_ conference.php

Sims, Norman (2007). True stories: A century of literary journalism. Evanston, Illinois: Northwestern University Press. ISBN: 9780810124691

Vogan, Travis; Dowling, David (2014). "Bill Simmons, Grantland.com, and ESPN's corporate reinvention of literary sports writing online". Convergence, online first. http://dx.doi.org/10.1177/1354856514550637

Whiteside, Erin; Hardin, Marie (2013). “The glass ceiling and beyond. Tracing the explanations for women's lack of power in sports journalism". En: Pedersen, Paul M. (ed.). Routledge Handbook of sport communication. Abingdon: Routledge, pp. 146-154. ISBN: 9780415518192

Wimmer, Roger D.; Dominick, Joseph R. (2011). Mass media research: An introduction ( $9^{\text {th }}$ ed.). Canada: Cengage Learning. ISBN: 9781439082744 